International Journal of Agriculture, Environment and Bioresearch

Vol. 5, No. 06; 2020

ISSN: $2456-8643$

\title{
HYGIENE AND SANITATION EQUIPMENTS AND THEIR IMPACTS ON THE HEALTH OF LEARNERS AT DAVIE TEACHING COLLEGE
}

\author{
BAMISSO Rafiatou ${ }^{1 \& 2}$ and KOUMAGNON Astrida ${ }^{1}$ \\ ${ }^{1}$ Ecole Normale Supérieure, University of Abomey-Calavi, Benin \\ ${ }^{2}$ Laboratory of Climatology, Pierre PAGNEY ' Climate, Water, Ecosystem and Development 'University of \\ Abomey-Calavi - 03 BP 1122 Jéricho Cotonou, Benin \\ https://doi.org/10.35410/IJAEB.2020.5584
}

\begin{abstract}
Around the world, environmental pollution is increasingly degrading the health of communities. This study aims to identify hygiene and sanitation problems and their impact on the health of learners at CEG Davié.

The research methodology is based on documentary research, field surveys and interviews. A total of 162 people were questioned, including 150 learners, 04 members of the administration, 07 teachers and 01 health worker.

The results obtained show that the CEG Davié does not have enough latrines, urinals according to $90 \%$ of learners, hand washing device according to $100 \%$ of learners, garbage management device according to $95 \%$ of respondents and that hygiene rules are not always observed. These situations expose the learners to different illnesses such as $36 \%$ malaria, 16\% cases of vomiting, $12 \%$ cases of diarrhea, $32 \%$ cases of stomach ache and $4 \%$ cases of skin infections. To avoid these different cases of illness, each actor in the education system must fully play his role.
\end{abstract}

Keywords: CEG Davié, equipments, hygiene, health, learners.

\section{INTRODUCTION}

The WHO (2003 p.46) shows that "in most countries of the world schools need to do more to improve the well-being and capacity of children and adolescents". In Benin, environmental governance is not yet a reality internalized by the populations of our towns and countryside. Public or private school infrastructures intended to accommodate learners do not always meet the environmental standards necessary to guarantee them adequate training. and with complete peace of mind (H. Abley, 2005, p.40).

According to J-B B. Gnanho (2008, p.68), the installation of places for acquiring knowledge, moral and civic education are in general subject to the mismanagement of space, to nonexistence or inadequate infirmaries, latrines, school canteens, which still endanger the health of learners. For example 400 million school-aged children per year suffer from infection caused by intestinal worms which, as research shows decrease their learning ability (UNICEF / IRC, 2011, p.54). In the CEG Davié for example, the problems of insalubrity are very remarkable and the 
learners are more and more exposed to various diseases. This study on school hygiene will allow the various authorities involved in the management of school space to keep their environment clean while teaching learners the adoption of cleanliness rules both at school and at home.

\subsection{Presentation of the study site}

The CEG Davié is located between $2^{\circ} 27 ' 52$ " and $2^{\circ} 27 ' 28$ " of the east longitude and between $6^{\circ} 28^{\prime} 16^{\prime \prime}$ and $6^{\circ} 28$ '26' 'of the north latitude with an area estimated at about 8 hectares. Figure 1 opposite shows the location of the CEG in the city of Porto-Novo.

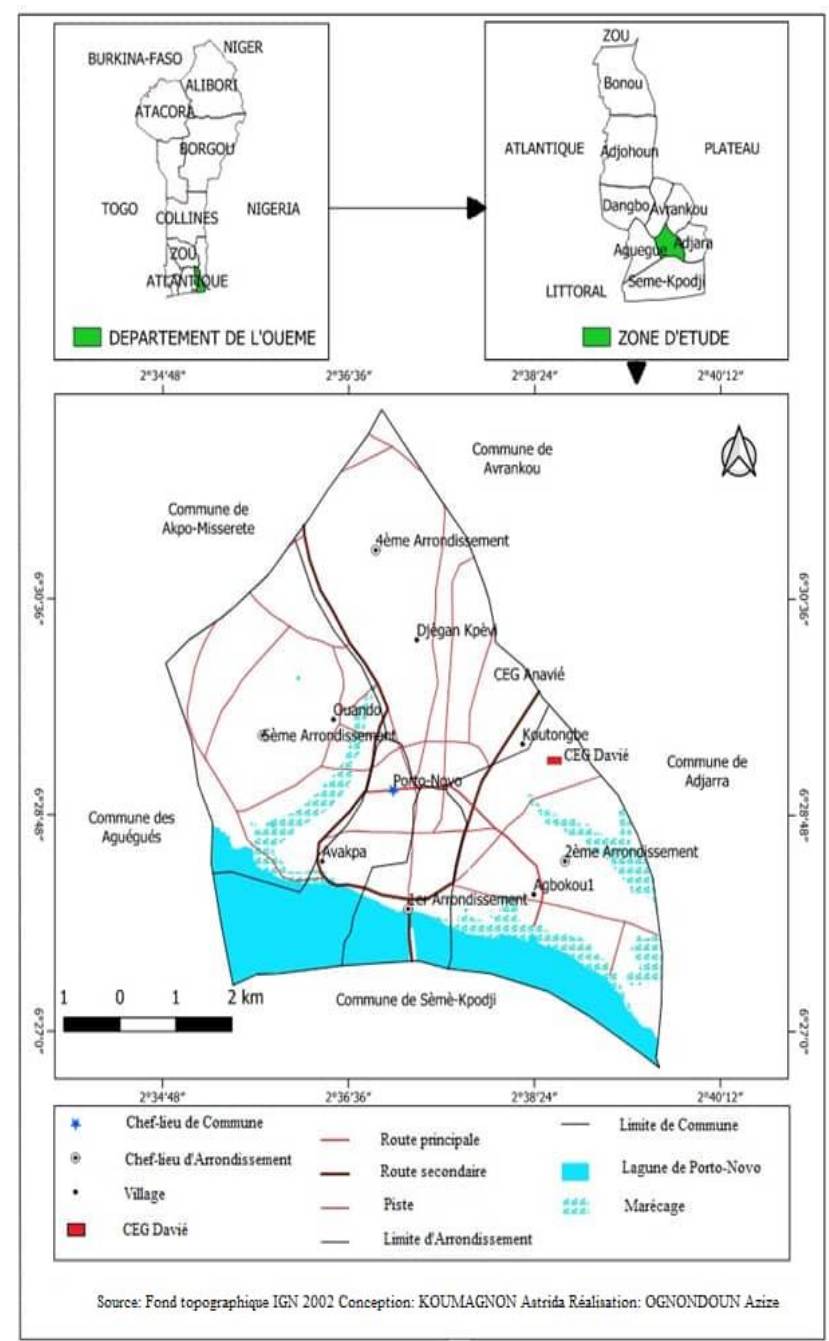

Figure 1: Location of CEG Davié in the city of Porto-Novo 


\section{STUDY METHODS}

As part of this study, certain information was collected in various documentation centers and specific structures. The data used are: the epidemiological data which made it possible to know different diseases contracted by the students of the college Data collection materials, consist of: Global Position System (GPS) for the georeferencing of the study site, the photographic apparatus for illustrative shots of hygiene equipment. In addition, the techniques used are among others: direct observation in the field made it possible to visit in particular canteens, places of garbage dumps, drinking water supply points, latrines, classrooms, etc.. As for the data collection tools, they consist of: questionnaires addressed to users (learners, teachers, college sales staff; interview guides for the director, censors, supervisor, nurse, etc. The tools used allowed to have a global vision on the management mechanisms of the health facilities of the college.

\section{RESULTS}

\subsection{Hygiene and sanitation infrastructures at CEG Davié}

One of the main problems observed in the CEG Davié compound is the lack of hygiene and sanitation infrastructure.

To ensure hygiene and sanitation in secondary schools, certain infrastructures are essential and constitute important elements that schools need to improve their educational activities. These are classrooms, latrines, handwashing devices, urinals, garbage management devices, bins and the canteen. The availability or lack of these hygiene and sanitation infrastructures at CEG Davié is presented in Table I below

Table 1: Inventory of hygiene and sanitation infrastructures at CEG Davié

\begin{tabular}{|l|l|l|}
\hline Name of infrastructures & Availability & deficit \\
\hline Classrooms & 52 & -54 \\
\hline Students latrines & 08 & -47 \\
\hline Hand washing devices & 00 & -55 \\
\hline Urinals & 00 & -55 \\
\hline Garbage management devices & 02 & -53 \\
\hline Wastes receptacles & 02 & -53 \\
\hline Canteen & 01 & 00 \\
\hline Water points & 03 & -52 \\
\hline Teachers latrines & 01 & -2 \\
\hline
\end{tabular}

Source: Fieldwork, April 2019 


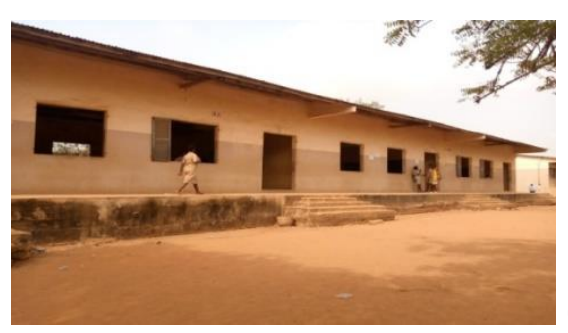

(1)

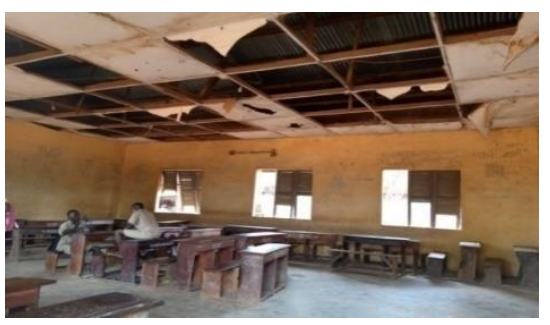

(2)

Board 1: classrooms (1) and shattered ceilings inside classrooms (2)

Photoshoot: Bamisso R., March 2019

\subsubsection{The absence of a urinal}

In the CEG Davié, no urinal exists. In fact, $90 \%$ of the learners surveyed declared that they had acquired the habit of urinating around latrines, in the open air or behind the classrooms and 10\% declared that they had made arrangements so as not to make themselves comfortable before leave college. According to the hygiene and sanitation standards set by WHO, fifty (50) learners are entitled to one (01) urinal cubicle.

\subsubsection{State of the latrines}

The choice of the location of the latrine is an important thing and requires careful consideration. At first glance, one might think that the hygienic conditions are respected. Note that only 02 blocks of 04 cabins were built for the 2795 learners, i.e. one (01) latrine699 learners in the CEG Davié. As for teachers; they have two (02) latrines which are not used properly because they are not well maintained. No handwashing facility water point is located near the latrines, resulting in the current state of the latrines. Board II shows the latrines and their interior in the college.

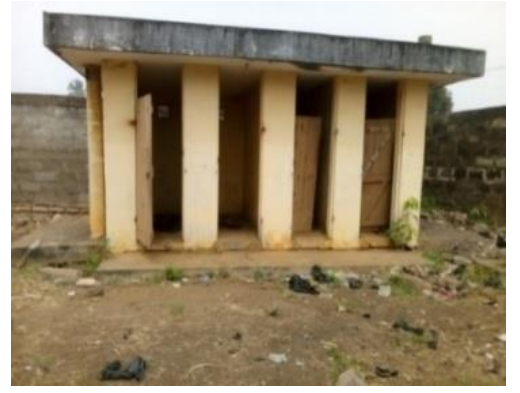

(1)

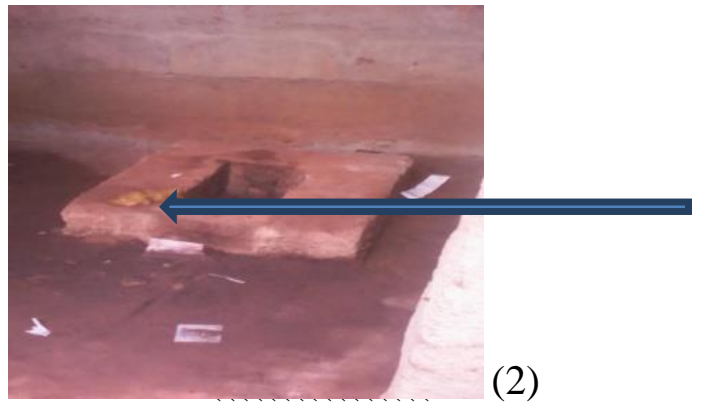

Board II: Functional latrines (1) and excrement on the edge of the WC (2) at CEG Davié Photoshoot: Bamisso R., March 2019

Learners who exploit it defecate at the edge because of the foul smell that emanates from it. Various problems are the cause of the state of the latrines: According to $40 \%$ of teachers and $39 \%$ of learners, it is about bad odors from the toilet, the state of neglect in which they are according to $28.73 \%$ of learners and $17,24 \%$ of teachers. Furthermore, $14.94 \%$ of learners and $10 \%$ of teachers feel they have no answer since they do not use these toilets. 


\subsubsection{Condition of the valves}

At CEG Davié, the hand washing system no longer exists. The latter was destroyed by the learners themselves due to misuse. In addition, there is a single point of water supply for learners and vendors. Board III shows the hand-washing system and the functional water point of the college.

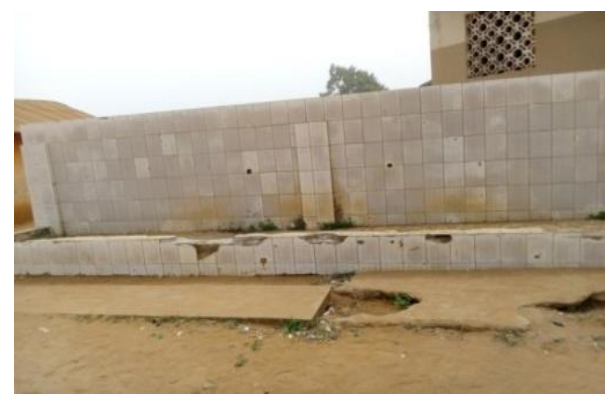

(1)

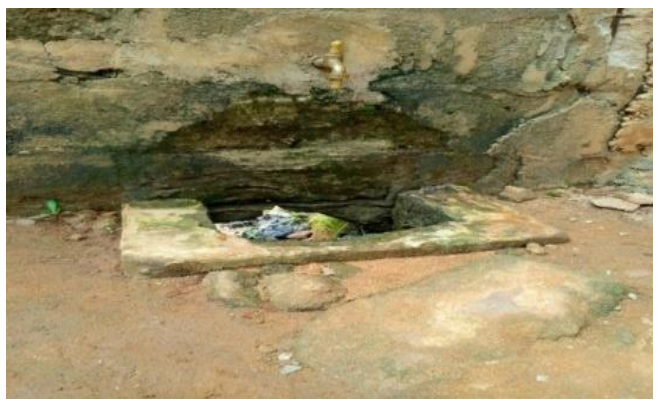

(2)

Board III: Functional latrines (1) and excrement on the edge of the WC (2) at CEG Davié Photoshoot: Bamisso R., March 2019

Learners who exploit it defecate at the edge because of the foul smell that emanates from it. Various problems are the cause of the state of the latrines: According to $40 \%$ of teachers and $39 \%$ of learners, it is about bad odors from the toilet, the state of neglect in which they are according to $28.73 \%$ of learners and 17, 24\% of teachers. Furthermore, $14.94 \%$ of learners and $10 \%$ of teachers feel they have no answer since they do not use these toilets.

\subsubsection{Condition of the valves}

At CEG Davié, the hand washing system no longer exists. The latter was destroyed by the learners themselves due to misuse. In addition, there is a single point of water supply for learners and vendors. Board IV shows the hand-washing system and the functional water point of the college.

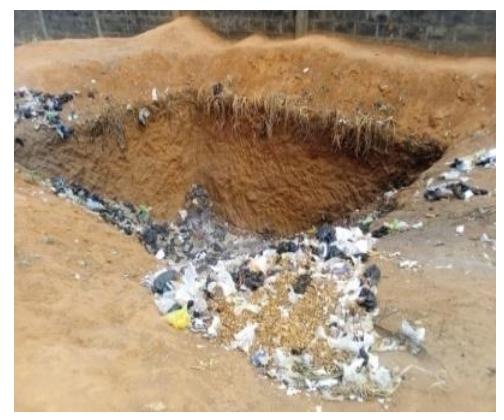

(1)

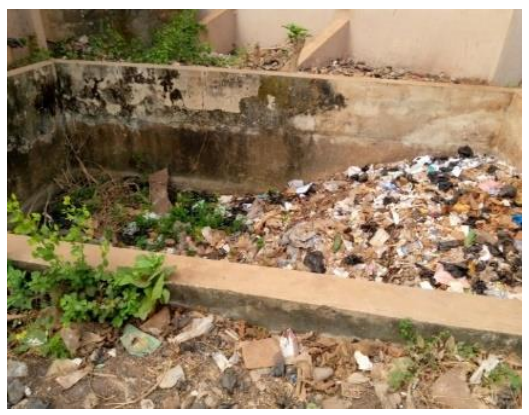

(2)

Board IV: Garbage management system at CEG Davié (1) and (2)

Photoshoot: Bamisso R., April 2019

The college has neither bins nor hygiene kits, but rather baskets and brooms which are made available to learners in each class for cleaning. In middle school, the disposal of this waste is 
done by the learners themselves although this can be complicated since the nature of the waste is much more diverse. But these learners try to burn this waste even though it makes them sick as it constitutes potential direct or indirect harm to both the physical environment and human health. Learners are thus exposed to real and permanent danger. The consequences of insalubrity are many and varied. Beyond their repulsive appearance, the garbage piles maintain a swarm of flies and other insects which are vectors of pathogenic germs. Table II shows the factors contributing to the insalubrity of Davié College.

Table II: Unhealthy factors in the college according to the respondents

\begin{tabular}{|c|c|c|}
\hline Insalubrity factors & Workforces & Frequencies \\
\hline $\begin{array}{c}\text { Overcrownding of the yard in the bags, paper and food crapes and } \\
\text { especially after recess }\end{array}$ & 57 & 48,72 \\
\hline Irregular garbage collection & 25 & 21,37 \\
\hline Dirty and poorly swept yard & 15 & 12,82 \\
\hline No bins in the yard & 10 & 8,55 \\
\hline No weeding of the yard and around the schools & 5 & 4,27 \\
\hline Pile of garbage near classrooms & 5 & 4,27 \\
\hline
\end{tabular}

Source: Fieldwork, April 2019

It emerges from the analysis of Table II that the state of insalubrity of the college is linked to the congestion of the yard by bags, papers, food scraps especially after recess according to $48.72 \%$ of the respondents and to irregular garbage collection according to $21.37 \%$ of respondents, which shows the dirtiness of the yard mentioned by $12.82 \%$ of respondents.

Indeed, $12.82 \%$ of respondents believe that the unhealthiness of the college is linked to the absence of garbage cans in the courtyard and the non-weeding of the courtyard and the surroundings of the college. In addition, $4.27 \%$ of respondents mentioned that the garbage piles are close to classrooms, which makes the college dirty and thus constitutes a source of the proliferation of mosquitoes, especially in the rainy season.

\subsubsection{Personal hygiene}

Personal hygiene is important for academic success. There is now evidence on the importance of proper hygiene habits, especially washing hands with soap at critical times after defecating and before eating or preparing food. Field surveys and works 
Almost $70 \%$ of parents of learners are illiterate and care very little about the hygiene of their children. Field surveys revealed the frequency of learners' daily baths in Figure 2 below.

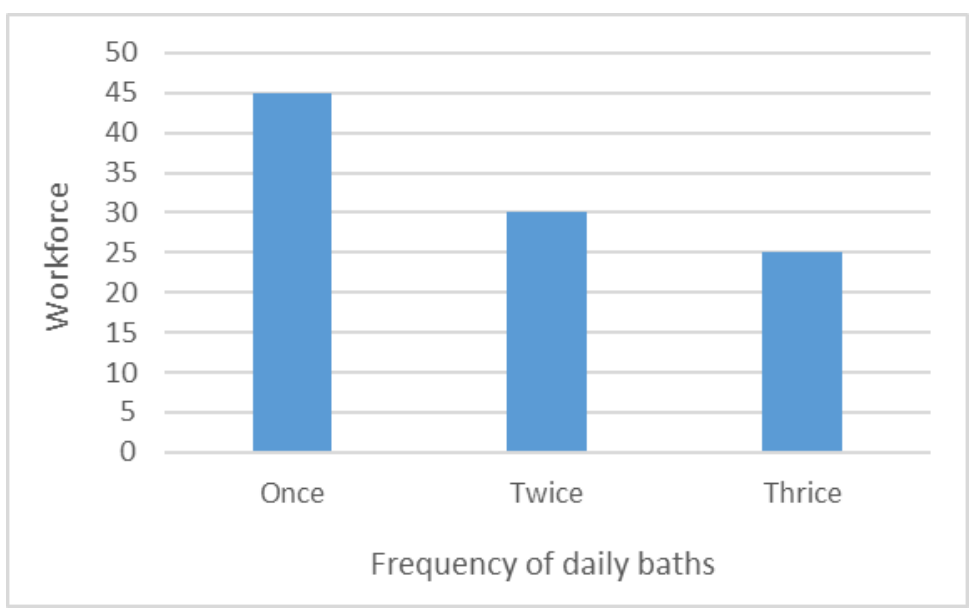

Figure 2: Personal hygiene by learners at CEG Davié

Source: Field surveys, April 2019

From the analysis of Figure 2, it emerges that $45 \%$ of learners take their baths once a day compared to $30 \%$ who take their baths twice a day and $25 \%$ three times a day. This aspect prevents them from being comfortable to work well and this has an impact on their health all the more so since the lack of personal hygiene is the source of certain skin diseases such as scabies, the cholera, typhoid fever, itching, etc.

\subsubsection{College food hygiene}

Food hygiene is provided by the food vendors in the canteen. However, there is a certain neglect in terms of hygiene at their level despite an obligatory annual medical examination which is imposed on them. Indeed, from the places of preparation to the school where these dishes are sold, it has been observed that the protective measures are not often respected, which thus expose these dishes to dust and to flies, vectors of several diseases. as shown in photo 1 opposite.

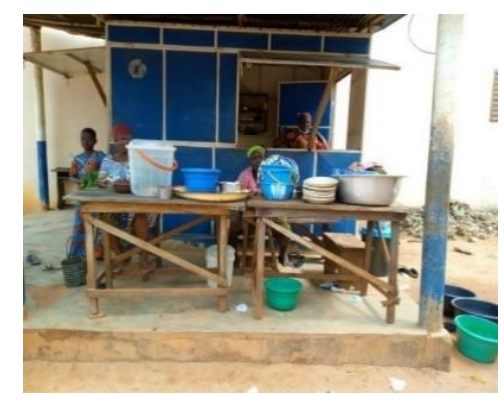

Photo 1: Exposure of food to dust in the CEG Davié canteen

Shooting: Bamisso R, April 2019 
According to $67.31 \%$ of learners, vendors do not protect their mouths and noses before selling food to them, so hands that take money are not cleaned before they serve them the food. Meals are not protected while the toilets and places of sale are very close together.

In such a condition, it is hardly surprising that learners are subject to evils which can be avoided if arrangements were made to make the school environment pleasant.

\subsection{Impacts of the state of hygiene and sanitation equipment on the health of CEG Davié learners}

Poor hygiene practices in the middle school expose learners to diseases such as malaria, stomach aches, diarrhea, etc. as shown in Figure 3 below.

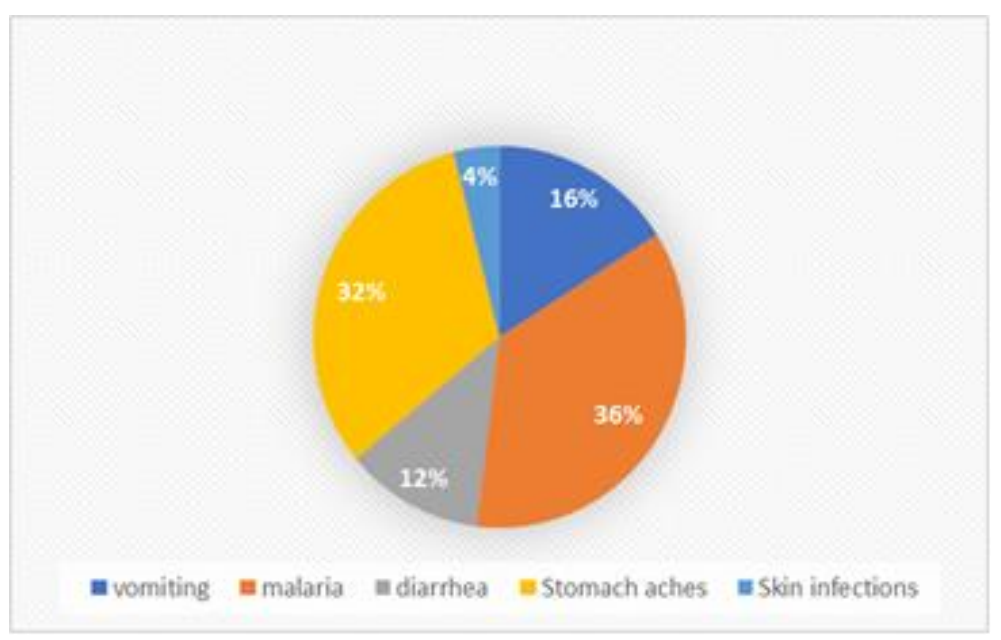

Figure 3: Frequency of the various diseases recorded in the Davié CEG

Source: Survey, April 2019

Analysis of Figure 2 shows that thirty-six percent $(36 \%)$ of the learners suffered from malaria, Thirty-two percent $(32 \%)$ from stomach ache, sixteen percent (16\%) from vomiting, twelve percent $(12 \%)$ diarrhea and four percent (4\%) skin infections during the school year.

\subsubsection{Malaria}

The vector responsible for this disease is the existence and location of garbage piles in relation to classrooms, resulting in the proliferation of mosquitoes which affects the health of learners. Thirty-six percent $(36 \%)$ of those surveyed revealed that they had suffered from malaria during the year. This phenomenon is more visible during the two periods of rainy seasons when the college is operational (first and third trimester of the school year).

\subsubsection{Stomach pain, vomiting and diarrhea}


The main causes of these ailments in the college are linked to the lack of food hygiene in the canteen and the quality of the water consumed. Thirty-two percent (32\%) of respondents admitted to having suffered from stomach aches, sixteen percent (16\%) from vomiting and twelve percent $(12 \%)$ had diarrhea during the school year.

\subsubsection{Skin infections}

Most of the time, they are linked to a lack of hygiene (personal hygiene, oral hygiene, clothing). In the college four percent $(4 \%)$ of respondents suffered from skin infections during the year. The most mentioned are among others lice, scabies, ticks, yeast infections, etc.

\section{DISCUSSIONS}

The research carried out contributes to a better knowledge and understanding of hygiene and sanitation in schools and its impacts on the health of learners.

At the end of this research, we retain that the school environment influences the health of learners. This is explained by the insalubrity mentioned by $95 \%$ of respondents. These results are similar to those of V.O. Azonnakpo (2007, p. 42) who worked in the Municipality of Porto-Novo where insalubrity and the lack of hygiene in schools are parameters responsible for diseases such as malaria, diarrhea, etc. as well as those P. C. Meliho (2004, p.55) who worked in the Municipality of Toffo where the lack of mastery of the concepts of hygiene and sanitation leads the populations to have sociological behaviors that influence their health.

The inexistence and insufficiency of hygiene and sanitation equipment are the source of several diseases (diarrhea, malaria, stomach aches, vomiting, skin infections) mentioned in the college. To ensure adequate sanitation in schools, access to safe drinking water and latrines with hand washing facilities outside the toilet are needed.

\section{CONCLUSION}

At the end of this study, it should be remembered that the environment is one of the factors that influence the health of learners. In the CEG Davié, the lack of adequate equipment (garbage cans, urinals, hand washing devices, etc.) and the poor maintenance of existing ones (latrines, classrooms, dumps, water point, etc. .) expose college users to cases of illnesses, the most common of which are malaria followed by gastrointestinal illnesses such as diarrhea, vomiting, stomach aches, skin infections, etc. Faced with all these situations, all college users have their score to play for the smooth running of educational activities because non-compliance with hygiene and sanitation rules is a perverse blow to the smooth running and success of the activities. teaching in schools. Thus, the college authorities must organize awareness sessions and be able to punish when certain learners violate the various provisions planned for better hygiene in the school environment.

\section{REFERENCES}

Abley Henri, 2005, Health and food hygiene in schools: Case of the municipality of ToriBossito. Thesis by CAPES, UAC / ENS / Porto-Novo, 43 p. 
Vol. 5, No. 06; 2020

ISSN: $2456-8643$

Sanitation in schools, The "child-to-child-IRC" approach published on 02/10/2012 consulted on 22/11/2019 at 11:50 p.m., 6 p.

Azonnakpo Vinassého Olivier, 2007, Problematic of water and sanitation in schools in the Republic of Benin: Case of the city of Porto-Novo University of Abomey-Calavi DESS in Decentralization and water management 2007 www.mémoireonline. com07 / 12/2016., accessed 27/01/2020.

Water, Hygiene and Sanitation in schools, 2017, Water solidarity program, information and discussion meeting on September 27, 2017 in Lyon www.pseau.org.eauhygiène et assainissement, accessed 02/13/2020

Gnanho Jean-Baptiste Blaise, 2007, Sanitation and hygiene problems in schools: Case of CEG1 and CEG2 in Abomey-Calavi. Thesis of CAPES, ENS, Porto-Novo, 68 p;

Meliho Pierre Codjo., 2004, Environment and health / socio-cultural approach to water-related diseases in schools in the town of Toffo, Master's thesis in sociology and anthropology, UAC, FLASH, $81 \mathrm{p}$.

UNICEF / IRC, 2011, PS-Water / Sanitation in Developing Countries, 91p.

WHO, 1997, Environmental health in urban planning. Report of a WHO expert committee, 807, Geneva, Paris 73 p.

Seke Toussaint, 2013, The impact of the living and working conditions of learners and teachers on school performance, CFPEEN, Porto-Novo, CAFCP thesis, $53 \mathrm{p}$. 